\title{
Resource landscapes explain contrasting patterns of aggregation and site fidelity by red knots at two wintering sites
}

Thomas Oudman ${ }^{1,2^{*}}$ D , Theunis Piersma ${ }^{1,3}$, Mohamed V. Ahmedou Salem ${ }^{4}$, Marieke E. Feis ${ }^{1,5}$, Anne Dekinga ${ }^{1}$, Sander Holthuijsen ${ }^{1}$, Job ten Horn', Jan A. van Gils ${ }^{1}$ and Allert I. Bijleveld ${ }^{1}$

\begin{abstract}
Background: Space use strategies by foraging animals are often considered to be species-specific. However, similarity between conspecific strategies may also result from similar resource environments. Here, we revisit classic predictions of the relationships between the resource distribution and foragers' space use by tracking free-living foragers of a single species in two contrasting resource landscapes. At two main non-breeding areas along the East-Atlantic flyway (Wadden Sea, The Netherlands and Banc d'Arguin, Mauritania), we mapped prey distributions and derived resource landscapes in terms of the predicted intake rate of red knots (Calidris canutus), migratory molluscivore shorebirds. We tracked the foraging paths of 13 and 38 individual red knots at intervals of $1 \mathrm{~s}$ over two and five weeks in the Wadden Sea and at Banc d'Arguin, respectively. Mediated by competition for resources, we expected aggregation to be strong and site fidelity weak in an environment with large resource patches. The opposite was expected for small resource patches, but only if local resource abundances were high.
\end{abstract}

Results: Compared with Banc d'Arguin, resource patches in the Wadden Sea were larger and the maximum local resource abundance was higher. However, because of constraints set by digestive capacity, the average potential intake rates by red knots were similar at the two study sites. Space-use patterns differed as predicted from these differences in resource landscapes. Whereas foraging red knots in the Wadden Sea roamed the mudflats in high aggregation without site fidelity (i.e. grouping nomads), at Banc d'Arguin they showed less aggregation but were strongly site-faithful (i.e. solitary residents).

Conclusion: The space use of red knots in the two study areas showed diametrically opposite patterns. These differences could be explained from the distribution of resources in the two areas. Our findings imply that intraspecific similarities in space use patterns represent responses to similar resource environments rather than species-specificity. To predict how environmental change affects space use, we need to understand the degree to which space-use strategies result from developmental plasticity and behavioural flexibility. This requires not only tracking foragers throughout their development, but also tracking their environment in sufficient spatial and temporal detail.

Keywords: Aggregation, Foraging, Heterogeneity, Intertidal, Movement, Predator-prey interactions, Red knots, Site fidelity, Time-of-arrival, Tracking

\footnotetext{
* Correspondence: thomas.oudman@gmail.com

${ }^{1} \mathrm{NIOZ}$ Royal Netherlands Institute for Sea Research, Department of Coastal Systems, and Utrecht University, P.O. Box 59, 1790 AB Den Burg, Texel, The Netherlands

${ }^{2}$ Centre for Biological Diversity, School of Biology, University of St Andrews,

Fife KY16 9TF, UK

Full list of author information is available at the end of the article
}

(c) The Author(s). 2019 Open Access This article is distributed under the terms of the Creative Commons Attribution 4.0 International License (http://creativecommons.org/licenses/by/4.0/), which permits unrestricted use, distribution, and reproduction in any medium, provided you give appropriate credit to the original author(s) and the source, provide a link to the Creative Commons license, and indicate if changes were made. The Creative Commons Public Domain Dedication waiver (http://creativecommons.org/publicdomain/zero/1.0/) applies to the data made available in this article, unless otherwise stated. 


\section{Background}

Outside of the reproductive period, the main reason for animals to move is to feed. In this situation, the distribution of resources across the environment is the main determinant of animal space use patterns [1]. Therefore, the fact that different populations of one species often have the same space use characteristics may not only be the consequence of similar physical and cognitive traits, but also of similar resource environments.

Resource environments can affect space use in several ways. Here, we distinguish between two types of space use patterns. First, the environment influences the degree of aggregation: spatial patterns in the locations of different animals across the landscape at a single point in time [2-5]. In that sense, aggregation can be quantified by a family of space use variables that include dispersion, group size, degree of sociality and inter-individual distances. Second, the environment also influences site fidelity: spatial patterns in the locations of single individuals over time [6-14]. In this sense, site fidelity includes space use measures such as dispersal, home range, return rate and exploration behaviour.

In theory, all combinations of aggregation and site fidelity are possible. For clarity, we plotted different space use patterns produced by foragers that choose between several discrete resource patches in a series of time steps (Fig. 1). The four panels represent the extreme cases, to which we refer as solitary residents (low aggregation and high site fidelity, Fig. 1a), grouping residents (high aggregation and high site fidelity, Fig. 1b), solitary nomads (low aggregation and low site fidelity, Fig. 1c) and grouping nomads (high aggregation and low site fidelity, Fig. 1d). Although all combinations are possible, different environments may favour different combinations of aggregation and site fidelity.

\section{Costs and benefits of aggregation and site fidelity in different environments}

A high degree of aggregation allows for shared vigilance for predators and decreases per capita predation risk [15]. It also enables the transfer of social information [16], for example on foraging opportunities [17]. The main cost of grouping by foraging animals is competition for resources. Competition for resources happens when foragers decrease each other's intake rate, which can result from resource depletion as well as from interference competition $[18,19]$. Resource competition will be generally be reduced when local resource abundance is higher

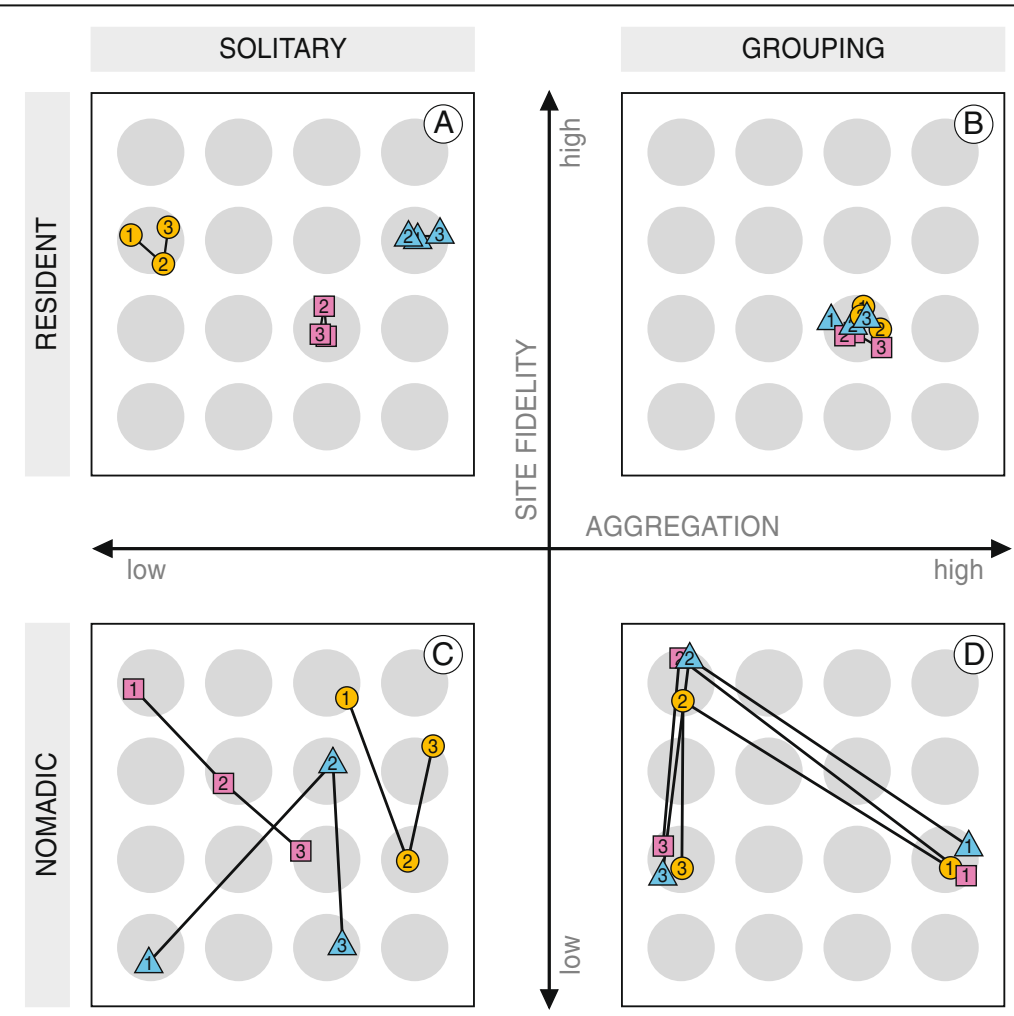

Fig. 1 Four extreme patterns of space use, with the degree of aggregation on the $x$-axis and the degree of site fidelity on the $y$-axis. For clarity, we named the four extremes solitary residents (a), grouping residents $(\mathbf{b})$, solitary nomads (c) and grouping nomads (d). Any intermediate pattern is also possible. Grey circles represent resource patches. Symbols denote three different individuals, and the thin lines connect subsequent positions of the same individual for three time steps, that are denoted by the numbers in the symbols. Individual positions within patches are arbitrary 
(less depletion) $[20,21]$ and when resource patch surface is larger (less interference) $[19,22]$. The optimal degree of aggregation will thus depend both on absolute local resource density and on resource patch size, i.e. the scale of spatial heterogeneity.

Site fidelity can be beneficial because it reduces variance in foraging success, for example when foragers return to good patches and stay away from bad ones [6]. Given that the resource environment is correlated over time, foragers are expected to show high site fidelity to specific patches when the difference in quality between foraging locations is high [23]. When the resource environment is not (or even negatively) temporally correlated, the relation between spatial heterogeneity and site fidelity is expected to reverse [6]. Then, high site fidelity is only expected if the spatial differences in quality are so low that it does not pay to search the environment for better patches [6]. Site fidelity becomes particularly costly when foraging has a strongly negative effect on the availability of resources. This can happen through depletion [24] or through predator avoidance behaviour by the prey [15].

When foraging has a negative effect on the availability of resources, both the abundance of foragers in a patch and the foraging time spent at one patch are constrained by local resource density $[2,6]$. For this reason, aggregation may negatively influence the optimal degree of site fidelity. A 'grouping resident' pattern of space use (Fig. 1b) may be expected only when local resource abundances are very high and competition is low or absent. If resources are less abundant, they may still occur in large patches and allow foragers to aggregate. In this case, however, effects of resource depletion will be strong and limit site fidelity, which results in a 'grouping nomad' pattern of space use (Fig. 1d). Territorial behaviour may counter the aggregation of conspecifics and allow high site fidelity, but only when patches are small and thus defendable [25-27]. As a result, a 'solitary resident' pattern of space use (Fig. 1a) is expected only when resources are distributed in small patches with high local resource abundances. When patches are small and contain so few resources that the prolonged presence of even one forager cannot be sustained, a 'solitary nomad' pattern of space use (Fig. 1c) may be the only option.

\section{Measuring aggregation, site fidelity, and the resource landscape in two contrasting environments}

Considerable variation in space-use patterns has been described within single species in response to different resource distributions, both in terms of aggregation [28-30] as well as in terms of site fidelity [31, 32], but not simultaneously. In this study, we measured both aggregation and site fidelity at two different wintering sites of a migratory shorebird, the red knot (Calidris canutus). At both sites, the red knots forage on mollusc prey in superficially similar intertidal habitats that nonetheless contrast in the spatial distribution of molluscs. In both areas, with radio tags, we collected detailed foraging tracks of individual red knots simultaneously, and performed detailed and spatially explicit resource sampling.

Previous studies have shown that the resource intake rates by red knots in the two areas are often not limited by search time or handling time, but instead by constraints on digestion and sulphide detoxification rate [33-36]. To compare the resource landscapes between the two areas, we therefore constructed spatial maps of the estimated potential energy intake rate (ash-free dry flesh mass) using a functional response model that was tailored for red knots in these specific areas and considers all these constraints [33-36]. The model was fitted to data from resource sampling. In addition, we analysed the contents of red knot droppings in both areas and considered only those mollusc species that comprised more than $1 \%$ of the estimated red knot's diet in terms of ash-free flesh mass. This method requires extensive sampling efforts and lab work (see methods) and relies on detailed experimental studies of prey choice, but it results in much more explicit and precise estimates than indirect indices of resource abundance, such as chlorophyll indices derived from satellite images [37-39].

The resource landscapes will yield predictions on differences in space-use patterns of red knots between the two areas. By comparing these predictions with the observed levels of aggregation and site fidelity, we investigated whether the distribution of resources could indeed affect the patterns of space use by red knots. The statistical significance of differences in the patterns of aggregation and of site fidelity were tested by a repeated randomization procedure [40], randomizing the red knot identity and tide of each itinerary and counting the proportion of randomizations in which a more extreme pattern occurred than the observed pattern.

\section{Methods}

\section{Tracking red knots}

Data was collected in the two main wintering areas of red knots along the East-Atlantic Flyway: the Wadden Sea in The Netherlands $\left(53^{\circ} 15^{\prime} \mathrm{N}, 5^{\circ} 15^{\prime} \mathrm{E}\right)$, and the Banc d'Arguin in Mauritania $\left(19^{\circ} 53^{\prime} \mathrm{N}, 16^{\circ} 17^{\prime} \mathrm{W}\right)$ [41]. These two populations, belonging to the subspecies C. c. islandica and C. $c$. canutus respectively, are very similar in morphology and genetically barely distinct $[42,43]$. The canutus knots stage in the Wadden Sea during north- and southward migration, where they likely occur in mixed flocks with islandica knots [41, 44] and cannot be told apart visually $[44,45]$. In the Wadden Sea in August, daily temperatures were roughly the same as at Banc d'Arguin in January, and 
given the similarity in the tidal movements, so would be daily energy expenditures [46].

Using a novel automated tracking system with a high resolution both in space and time $[47,48]$, detailed tracks of individual red knots were collected in both areas. From a previously published study in the Dutch Wadden Sea [49], we used data from 13 red knots tracked between 12 and 26 August 2011. From a similar study at Banc d'Arguin [50], we used data from 38 red knots that were tracked between 9 January and 13 February 2013. In the Wadden Sea we tracked the subspecies C. c. islandica, which spends the winter in intertidal systems in north-western Europe, including the Wadden Sea. At Banc d'Arguin, tracked red knots were of the subspecies $C$. c. canutus, which winters in in West-Africa, with a majority at Banc d'Arguin, and with some staging in the Dutch Wadden Sea in late summer when returning from the breeding grounds in Taimyr, north-central Siberia $[44,51]$.

The $6.5 \mathrm{~g}$ radio tags (ranging from 5.5 to $7.5 \mathrm{~g} ;<5 \%$ of body mass) were glued on the rump with Superglue [52]. Every second the tags emitted an individual-specific radio signal, to be received by an array of receiver stations in the study area. When received by at least three receiver stations, the tag's location was calculated from arrival times at the different stations $[48,53]$ and stored in a database.

\section{From tracking data to foraging itineraries}

During low tide, red knots move over intertidal mudflats in search of buried mollusc prey, which they find by repeated probing of the sediment with their ca. $3.5 \mathrm{~cm}$ long bill [54-56]. As the tide retreats, red knots fly to foraging locations, roughly $100 \mathrm{~m}$ to $10,000 \mathrm{~m}$ away from the roost, and visit one or several different locations before returning to the roost when the water returns $[49,50]$. After landing, red knots search for prey on foot, and may walk $100 \mathrm{~m}$ or more between flights. Hence, red knots search for resources on two spatial scales. They move between foraging locations by flight, and move on foot within these locations. In accordance with this typical pattern of movement, individual foraging itineraries were described as a sequence of patch visits during a single low tide period [49]. To this end the raw position data were summarized into a series of residence patch visits during each low tide period $(2 \mathrm{~h}$ before to 2 $\mathrm{h}$ after low tide). This was done in four steps. First, the raw position data was median-filtered using a 5-point sliding window. Then, using the method described by Barraquand \& Benhamou [14], the duration of stay within $125 \mathrm{~m}$ of each position was calculated, reflecting half the distance between resource sampling stations as well as roughly the red knots' scale of movement by flight. Excursions outside the radius for less than $30 \mathrm{~s}$ were allowed. The resulting sequence of "residence times" was segmented by the penalized contrasts method [57] into locations with an arrival and departure time. Finally, adjacent residence patches closer than $125 \mathrm{~m}$ were combined into one residence patch. Patch visits shorter than 10 min were not used in the analysis, because birds were then probably travelling rather than foraging [49]. The subsequent patch visits of a single bird during a single low tide period were defined as one foraging itinerary. This resulted in 144 foraging itineraries of 13 different birds in the Wadden Sea, and 1323 itineraries of 38 birds in the Banc d'Arguin. For further details we refer to Bijleveld et al. [49] for the Wadden Sea study and Oudman et al. [50] for the Banc d'Arguin study. The much lower number of itineraries in the Wadden Sea was due to technical issues that are inherent to the use of a prototype system, which concerned tag water-resistance and radio receiver software. These issues were resolved in the later study at Banc d'Arguin. Field observations in both study areas in subsequent years suggested that tagged red knots did not suffer from higher mortality than other colour-ringed red knots (TO, AIB and JtH, unpublished data).

\section{Measuring aggregation and site fidelity}

A common problem with absolute measures of aggregation (e.g. group size or distance to the nearest neighbour) from tracking data is that all individuals in the area must be tracked to derive an accurate estimate. We avoided this problem by assuming that the tagged birds mixed with the non-tagged birds (as field observations in both areas confirmed) and using a relative measure of aggregation. First, we computed the pairwise mean distances of each itinerary to all other itineraries, regardless by which individual and in which low tide period the itineraries had been made. That resulted in $\left(\begin{array}{c}144 \\ 2\end{array}\right)=10,296$ mean distances in the Wadden Sea and $\left(\begin{array}{c}1323 \\ 2\end{array}\right)=874,503$ mean distances in Banc d'Arguin. Then, we calculated whether the mean distance between all pairs of itineraries in the same low tide period (middle boxes in Fig. 2) were smaller than the mean distance between all combinations of itineraries at different low tide periods (left boxes in Fig. 2). Similarly, we used a relative measure of site fidelity: we calculated whether the mean distances between all pairs of itineraries of the same individual (right boxes in Fig. 2) were smaller than the mean distances between all combinations of itineraries from different individuals (left boxes in Fig. 2) [40, 58]. Applying this method to the simulated data from the conceptual model (Fig. 1), shows that it allows for the identification of solitary residents (Fig. 2a) and grouping nomads (Fig. 2c). It also shows that whether animals are classified as grouping residents (Fig. $2 \mathrm{~b}$ ) or as solitary nomads (Fig. 2d) depends on the scale of observation; both cases show no difference between the categorized mean distances. 


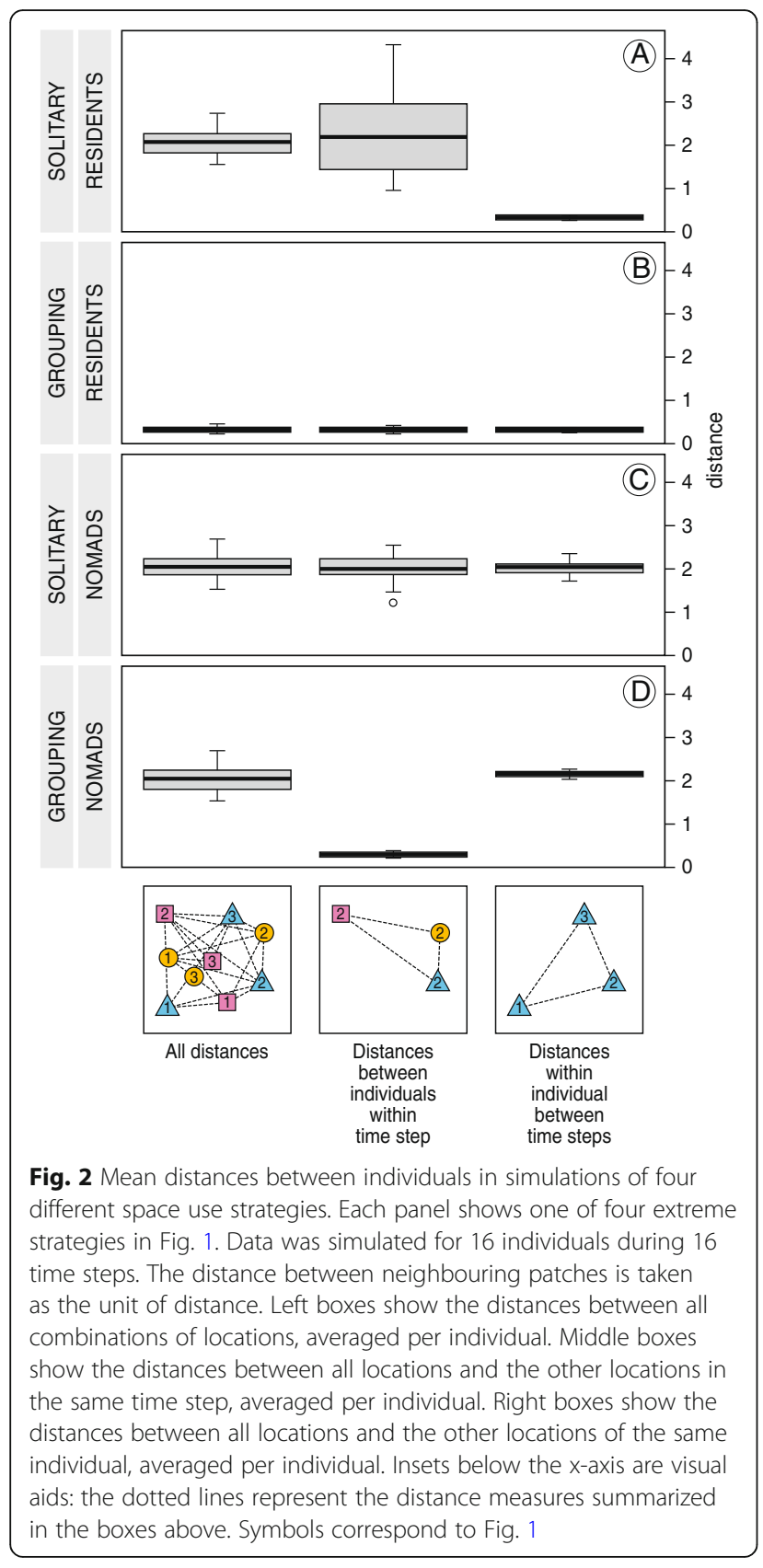

To compute an absolute measure of the mean distance between two itineraries, the distance between them was calculated each $5 \mathrm{~min}$ from $2 \mathrm{~h}$ before to $2 \mathrm{~h}$ after low tide, as the distance between the patch location in the first itinerary to the nearest patch location in the second itinerary within one hour. These distances were averaged to obtain a single mean distance between the two itineraries. An earlier analysis of the Banc d'Arguin data showed that red knots moved less during the day than during the night $[50,59]$. To avoid an effect of this temporal trend on the estimate of site fidelity, daytime locations were only compared with other daytime locations and night time locations were only compared with other locations at night. Locations recorded in the hour before sunrise and after sunset were not used at all. Mean distances between itineraries of different birds in the same low tide period (middle boxes in Fig. 2) were calculated by averaging for each itinerary the distances to all itineraries by other birds in the same tide. Likewise, mean distances between itineraries within birds in different low tide periods (right boxes in Fig. 2) were calculated by averaging, for each itinerary, the distances to all other itineraries by the same bird.

Due to the complex structure of the data, significance of the observed differences between the mean distances of all itineraries and the mean distances between individuals within tides (to show aggregation), as well as the differences between mean distances of all itineraries and the mean distances within individuals between tides (to show site fidelity), was tested by a repeated $(10,000$ times) randomization procedure [40, 60]. For each randomization, all tag-IDs and tide-IDs from the original itineraries were randomly re-assigned, the distances between all pairwise combinations of itineraries calculated and then averaged per itinerary, to arrive at a randomized estimate for the average distance between itineraries. To calculate a randomized estimate for its difference with between-individual distances within tides, tide-IDs were randomized per individual, all pairwise distances between itineraries within the same tide calculated, and then averaged per itinerary. To arrive at a randomized estimate for mean distances within individuals between tides, tag-IDs were randomized per tide, all pairwise distances between itineraries within the same tag calculated, and then averaged per itinerary [40]. Significance of the aggregation pattern and the site fidelity pattern was assessed in both areas independently by calculating the proportion of simulations that resulted in a more extreme difference than the actual observed difference (two-tailed $p$-value). To assess significance of differences between the Wadden Sea and Banc d'Arguin, mean distances were averaged per tag to arrive at independent observations, and tested by linear regression.

\section{Resource sampling}

The mollusc food of red knots was sampled at 880 locations in the Wadden Sea between 15 and 19 July 2011, and at 265 locations at Banc d'Arguin between 4 and 17 January 2013. Both sampling schemes consisted of a 250 $\mathrm{m}$ grid with a spatial accuracy of approximately $10 \mathrm{~m}$, with an additional $20 \%$ locations placed randomly on the grid lines $[49,61]$. Samples were taken by pushing a core into the sediment to at least $20 \mathrm{~cm}$ depth, and sieving the top $4 \mathrm{~cm}$ over a $1 \mathrm{~mm}$ mesh (either one core with a surface of $1 / 56 \mathrm{~m}^{2}$ or two cores of $1 / 112 \mathrm{~m}^{2}$ ). All molluscs were 
collected and stored in $4 \%$ formaldehyde, except for bivalves longer than $8 \mathrm{~mm}$ in the Wadden Sea, which were frozen.

All individual molluscs were identified to the species level, and length was measured to the nearest $0.1 \mathrm{~mm}$. Dry mass of the shell $\left(\mathrm{DM}_{\text {shell }}\right)$ and ash-free dry mass of the flesh $\left(\mathrm{AFDM}_{\mathrm{flesh}}\right)$ was measured in a subset of the samples as described by Piersma et al. [62]. Individuals below $8 \mathrm{~mm}$ (Wadden Sea) and $5 \mathrm{~mm}$ (Banc d'Arguin) in length were pooled before weighing when in the same sample. With small Limecola balthica, Ensis directus and Mya arenaria, flesh and shell were weighed together, and the ash-free dry mass of the flesh was estimated with calibration lines from Zwarts [63]. The gastropod Peringia ulvae was also weighed as a whole, assuming that $12.5 \%$ of organic matter resided in the shell [64]. For bivalve species weighed whole, $\mathrm{DM}_{\text {shell }}$ and AFDMflesh of the unweighted individuals were estimated by non-linear local regression of the log-transformed masses and lengths of the weighed individuals [65].

To determine which potential prey species contributed to the diet of red knots, we analyzed the composition of the droppings and calculated the relative contribution of different prey species to the diet $[66,67]$. Droppings were collected in the field at locations where radio-tagged red knots were observed foraging (2-10 droppings at 32 locations in the Wadden Sea and 45 locations in Banc d'Arguin). The droppings were aggregated per location and sieved over a $300 \mu \mathrm{m}$ mesh. All bivalve hinges and last coils of gastropods were identified to the species level and measured. Each measurement was converted to an estimated $\mathrm{AFDM}_{\text {flesh }}$ mass, using species-specific calibration measurements of whole individuals $[66,67]$.

\section{Calculating potential resource intake rates}

Potential intake rates $\left(\mathrm{mg} A F D M_{\text {flesh }}\right.$ per second) of the relevant mollusc species were estimated at each sampling station as a function of the observed densities. The estimates were calculated with an experimentally tested functional response model for red knots that forage on mollusc prey, taking into account search time and size- and species-dependent handling time and digestive quality of the prey [33]. It also accounts for the fact that the main available prey species at Banc d'Arguin, Loripes lucinalis, contains high levels of sulphur and/or sulphur-compounds that limit the intake by red knots [34-36]. The model also takes into account that digestion rate by red knots varies among individual red knots [68] and scales to the square of gizzard mass [33, 69]. Gizzard masses were measured by ultrasonography $[70,71]$ immediately after the catch, and were lower in the Wadden Sea (mean \pm SD, $7.0 \pm 2.0 \mathrm{~g}$ ) than at Banc d'Arguin $(8.5 \pm 1.8 \mathrm{~g})$. Only those prey species that were estimated to comprise at least $1 \%$ of the red knots diet, in terms of AFDM $\mathrm{flesh}_{\text {were }}$ considered. A more detailed explanation of the functional response model and its parameterization is given in Additional file 1: Appendix 1.

\section{The distribution of resources}

To determine the range of autocorrelation in the resource landscape, spatial autocorrelation in the predicted AFDMflesh intake rates was calculated at discrete distances of 50 $\mathrm{m}$ with the function "correlog" in R-package "ncf" [72], using Moran's $I$ index as the measure of autocorrelation $[49,73,74]$. The autocorrelation range was estimated by the distance at which the spatial autocorrelation went below 0.1, which can be interpreted as a measure of resource patch size [73].

\section{Results}

\section{Aggregation and site fidelity of tagged red knots}

In the Wadden Sea, mean distances between red knot itineraries in the same tide were significantly smaller than the mean distances between all combinations of itineraries (on average $1900 \mathrm{~m}$ and $2500 \mathrm{~m}, p<0.001$, Fig. 3a), meaning that they aggregated in some part of the total foraging range during each low tide. The tagged red knots did not show site fidelity in the Wadden Sea, as mean distances between itineraries of the same bird were not significantly smaller than the mean distances between all combinations of itineraries (both $2500 \mathrm{~m}$ on average, $p=0.09$, Fig. 3a). These differences agree with the differences in the simulated data of grouping nomads (Fig. 2d). Maps of red knot locations are provided as Additional file 1: Figure A2.

In contrast, red knots at Banc d'Arguin showed strong site fidelity, as mean distances between all combinations of itineraries of the same bird were much smaller than mean distances between all combinations of itineraries (on average $600 \mathrm{~m}$ and $1600 \mathrm{~m}, p<0.01$, Fig. 3b). Red knots at Banc d'Arguin also did aggregate, but the area used per tide was only slightly smaller than the area used by the study population. Distances between itineraries of birds in the same tide were on average $100 \mathrm{~m}$ smaller than distances between all combinations of itineraries ( $1500 \mathrm{~m}$ and $1600 \mathrm{~m}, p=0.01$, Fig. $3 \mathrm{~b})$. These differences agree best with the simulated data of solitary residents (Fig. 2a).

Note that all absolute distances averaged per bird were larger in the Wadden Sea than at Banc d'Arguin (2500 and $\left.1600 \mathrm{~m}, \mathrm{~F}_{1,49}=27.3, p<0.001\right)$, suggesting that overall the tagged red knots used a larger area within the range covered by the receiver stations in the Wadden Sea than at Banc d'Arguin. Average distances between tagged birds within the same tide were also larger in the Wadden Sea than at Banc d'Arguin (1800 and $1500 \mathrm{~m}, \mathrm{~F}_{1,49}=4.5$, $p=0.04)$. 


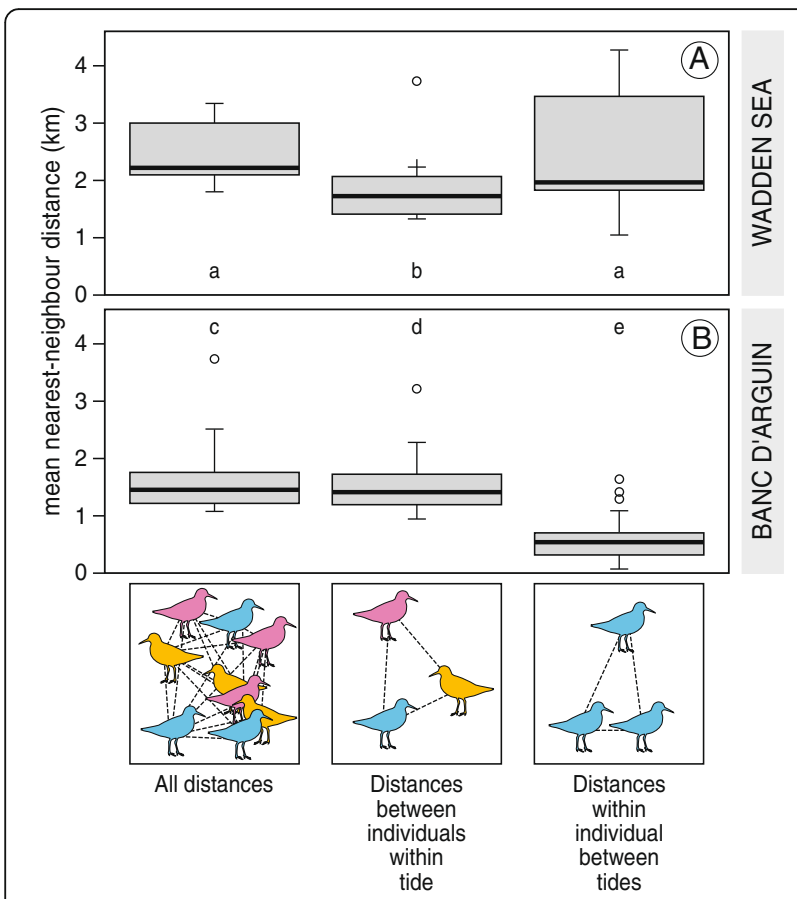

Fig. 3 Aggregation and site fidelity of red knots in the Wadden Sea and at Banc d'Arguin. Shown are the mean distances between all itineraries (left), the mean distances between itineraries of the same bird in different low tide periods (middle, a measure of site fidelity), and mean nearest-neighbour distances between itineraries of different birds during the same low tide (right, a measure of aggregation). Data is averaged per bird. Boxes $a, b, c$, $d$ and e differ significantly from each other. Significance was assessed by repeatedly (10,000 times) drawing a random sample from all mean distances shown in the left boxes. Insets below the $x$-axis are visual aids, as in Fig. 2: the dotted lines represent the distance measures summarized in the boxes above. In the bird-symbols, each color represents one individual

\section{Resource densities and resource patch sizes}

Maximum resource densities, in terms of available ashfree dry flesh mass per square meter, were much larger in the Wadden Sea $\left(26.2 \mathrm{~g} \mathrm{AFDM} / \mathrm{m}^{2}\right)$ than in Mauritania $\left(7.7 \mathrm{~g} \mathrm{AFDM} / \mathrm{m}^{2}\right)$. Red knots' intake rate was estimated to be constrained by digestive capacity at $22 \%$ of the sampling locations in the Wadden Sea, compared to $4 \%$ at Banc d'Arguin. At Banc d'Arguin, the toxin constraint on the intake of Loripes lucinalis was estimated to limit intake rate at $48 \%$ of the sampling locations. Due to these constraints, the mean potential resource intake rates were similar in the two areas (Fig. 4, mean \pm SD, 0.07 $\pm 0.10 \mathrm{mg} \mathrm{AFDM} / \mathrm{s}$ in the Wadden Sea and $0.09 \pm 0.08$ $\mathrm{mg}$ AFDM/s on Banc d'Arguin, $p>0.1$ ). Also the $95 \%$ quantile was similar $(0.26 \mathrm{mg} \mathrm{AFDM} / \mathrm{s}$ in the Wadden Sea, and $0.25 \mathrm{mg}$ AFDM/s on Banc d'Arguin). However, the intercept as well as the range of spatial autocorrelation in the potential resource intake rate was strikingly different between the Wadden Sea (intercept $=0.97$, range $=1700 \mathrm{~m}$ ) and Banc d'Arguin (intercept $=0.18$, range $<50 \mathrm{~m}$, Figs 4 and 5, Table 1). Hence, the size of resource patches strongly differed. In the Dutch Wadden Sea, estimated patch size was on average larger $(1700 \mathrm{~m})$ than at Banc d'Arguin (50 $\mathrm{m}$, the minimum resolution allowed by the measurements, Fig. 5, Table 1).

Because resource patches were smaller than the intersample distance, the resource sampling scheme at Banc d'Arguin is likely to have missed foraging patches (Figs 4 and 5). Additional sampling of specific locations where tagged red knots were observed foraging showed that they indeed discovered locations where potential energy intake rate was higher than the values obtained for the sampling grid (Additional file 1: Appendix 2, Additional file 1: Figure A1). The analysis of droppings showed

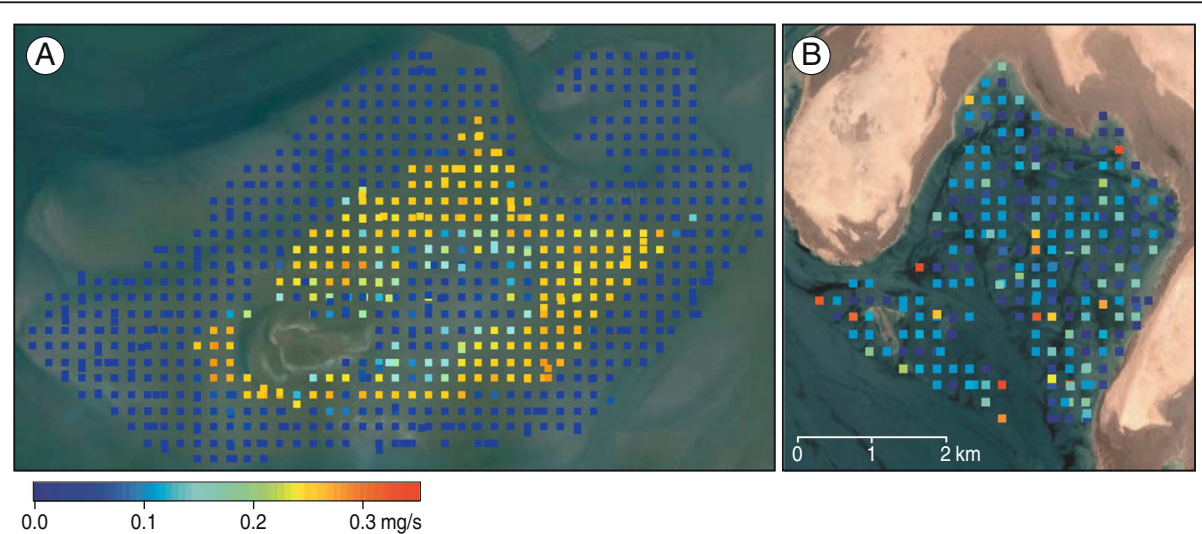

Fig. 4 Intake rate by red knots in the Wadden Sea (a) and at Banc d'Arguin (b) predicted on the basis of estimates of food abundance using grid-sampling. The two maps are to scale, and each square represents one sampling location. The potential intake rate of ash-free dry flesh mass (AFDM flesh) was calculated by an experimentally tested diet choice model. Calculations were based on mollusc species making up at least $1 \%$ of the red knot's diet (Table 1). Differences in mean digestive capacity between the tagged Wadden Sea and Banc d'Arguin red knots were considered 


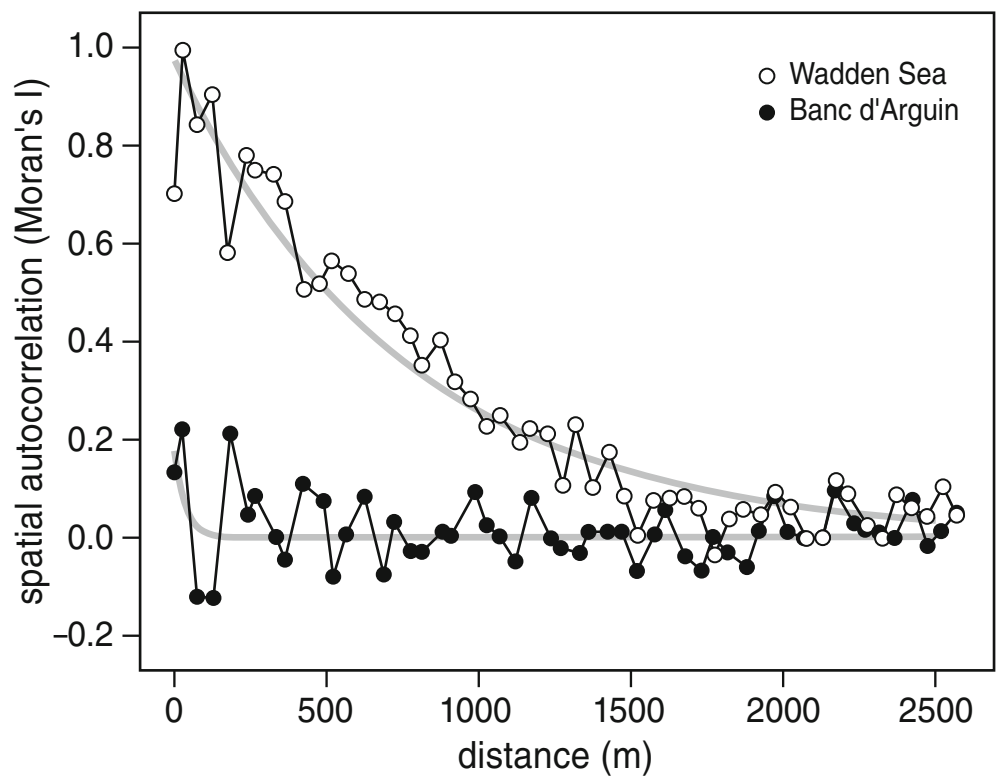

Fig. 5 Correlogram of estimated maximum AFDM flesh intake rates in the Wadden Sea and at Banc d'Arguin. Spatial autocorrelation was estimated by calculating Moran's / values, based on the estimated potential AFDM flesh intake rates at the sampling stations (see Fig. 4). Grey lines show exponential regression of the Moran's / values

that during the tracking period, red knots in the Wadden Sea had a virtually monospecific diet, which for more than $99 \%$ of the estimated consumed ash-free dry flesh mass consisted of common cockles, Cerastoderma edule (Table 1). At Banc d'Arguin, four different species each contributed more than $10 \%$ to the diet, and $95 \%$ all together (Table 1). In addition, on average $15 \%$ of the dropping dry mass at Banc d'Arguin consisted of plant material (ranging between 0 and $85 \%$ ), presumably rhizomes of seagrass Zostera noltii.

Table 1 Diet proportion, availability and spatial autocorrelation of molluscs in the Wadden Sea and at Banc d'Arguin

\begin{tabular}{|c|c|c|c|c|c|}
\hline Species $^{a}$ & Proportion in diet ${ }^{\mathrm{b}}$ & Numerical density $\left(1 / \mathrm{m}^{2}\right)$ & $\operatorname{AFDM}_{\text {flesh }}\left(\mathrm{mg} / \mathrm{m}^{2}\right)$ & Autocor. intercept & Autocor. range ${ }^{c}(\mathrm{~m})$ \\
\hline \multicolumn{6}{|l|}{ Wadden Sea } \\
\hline Cerastoderma edule & 0.99 & 762 & 760 & 0.51 & 900 \\
\hline Limecola balthica & $<0.01$ & 31 & 268 & 0.04 & 0 \\
\hline Peringia ulvae & $<0.01$ & 427 & 134 & 0.52 & 1600 \\
\hline Ensis directus & $<0.01$ & 35 & 70 & 0.26 & 600 \\
\hline Mya arenaria & $<0.01$ & 40 & 38 & 0.44 & 1100 \\
\hline Abra tenuis & $<0.01$ & 36 & 34 & 0.52 & 700 \\
\hline AFDM $M_{\text {flesh }}$ intake rate $(\mathrm{mg} / \mathrm{s})^{\mathrm{d}}$ & & & & 0.97 & 1700 \\
\hline \multicolumn{6}{|l|}{ Banc d'Arguin } \\
\hline Loripes lucinalis & 0.49 & 251 & 1337 & 0.63 & 400 \\
\hline Diplodonta circularis & 0.19 & 8 & 101 & 0.03 & 0 \\
\hline Dosinia isocardia & 0.13 & 25 & 77 & 0 & 0 \\
\hline Abra tenuis & 0.14 & 32 & 31 & 0.65 & 0 \\
\hline Senilia senilia & 0.06 & 6 & 29 & 0.15 & 200 \\
\hline AFDM $M_{\text {flesh }}$ intake rate $(\mathrm{mg} / \mathrm{s})^{\mathrm{d}}$ & & & & 0.18 & 50 \\
\hline
\end{tabular}

${ }^{\mathrm{a}}$ Only mollusc species with more than $10 \mathrm{mg} \mathrm{AFDM} \mathrm{M}_{\text {flesh }}$ per $\mathrm{m}^{2}$ that are in the upper $4 \mathrm{~cm}$ of the sediment and ingestible by red knots

${ }^{\mathrm{b}} \mathrm{AFDM}$ flesh proportion of all listed mollusc prey in the diet, based on dropping data (hinge measurements)

${ }^{C}$ Range is defined as the distance at which the spatial autocorrelation drops below 0.1. The autocorrelation function is estimated by exponential regression of the Moran's $I$ index at discrete distances. Species specific autocorrelation functions are based on the summed AFDM $_{\text {flesh }}$ density at each location

${ }^{\mathrm{d}}$ Autocorrelation function of the predicted intake rate (see Fig. 5), taking in account only those prey species that had an estimated average proportion of more than 0.01 in the diet 


\section{Discussion}

Red knots encountered larger resource patches and higher local resource abundances in the Wadden Sea than at Banc d'Arguin. Predicted energy intake rates were similar due to constraints set by digestive capacity. In line with expectations, the differences coincided with stronger aggregation by red knots in the Wadden Sea and stronger individual site fidelity by red knots at Banc d'Arguin. Whereas the Wadden Sea red knots are best described as grouping nomads (Fig. 1d), the Banc d'Arguin red knots are at the other side of the space-use spectrum and are best described as solitary residents (Fig. 1a). This result suggests that space use patterns do not simply reflect the physical and cognitive traits of red knots; instead, red knots adjust the pattern of space use to the distribution of resources. Below, we discuss alternative explanations for the patterns observed. In particular, we discuss the potential influences of predation risk, individual diet specializations and information use in explaining the observed differences between the areas. But first, we discuss some limitations of the methods.

\section{From a relative to an absolute measure of aggregation}

Our method did not provide an absolute measure of aggregation. For example, the mean distances between tagged birds (middle boxes in Fig. 3) do not signify inter-individual distances within groups, because they also include the distances between birds in different groups. Also note that the mean distances between tagged birds in the area (y-axis in Fig. 3) must be much larger than the mean distances to other conspecifics in general, because we tracked only a fraction of all red knots in the area. Our method provided a measure of aggregation that is relative to the total area used by all of the tracked individuals. What we have shown is that red knots in the Wadden Sea generally aggregated in a part of their total used area, whereas the Banc d'Arguin red knots generally spread out across their total used area.

Limitation of the intake rate model: Unknown food types Apart from different species of molluscs, at Banc d'Arguin red knot droppings also contained varying amounts of plant material, probably the rhizomes of intertidal seagrass (Zostera noltii). Unfortunately, this type of resource cannot be accounted for in the current intake rate models, as energy content of seagrass rhizomes as well as red knots' search efficiency, handling time, digestive rate and digestion efficiency on this food type have not been measured yet. However, previous studies have argued that seagrass rhizomes contain less nutrients and should be harder to digest by red knots than bivalve flesh [55]. Preliminary experiments confirmed that red knots switch to foraging on seagrass rhizomes only when bivalve densities are very low (JAvG, unpublished data). Hence, the most likely scenario is that red knots only feed on seagrass when bivalve prey is insufficient. Because of this low preference, and the high availability and visibility of seagrass, we expect that it is of minor importance in explaining the space use of red knots. Clearly, further research is needed to confirm this assumption.

\section{Predation risk}

The resource distribution is expected to be the prime determinant of forager movement decisions, as resources are the reason for foragers to move in the first place [75]. As the resource abundance becomes less limiting, predation risk is expected to become a more important determinant of space use [76]. Indeed, predation risk can be a main determinant of habitat quality for red knots at Banc d'Arguin [50, 77] as well as the Wadden Sea [62]. However, we think that the large differences in space use between Banc d'Arguin and the Wadden Sea are unlikely to be explained by differences in predation risk [75]. Being depredated mainly by falcons, which attack by surprise from behind concealing habitat structures such as ridges of dunes, predation pressure will be relatively low when foraging on the offshore intertidal mudflats [78]. In accordance with that, predation is thought to mainly take place in the two hours before high tide [79], a period that was not included in the analyses. Moreover, even when spaced out, shorebirds maintain the potential to coalesce into tight flocks when necessary [28, 80].

\section{An information-based approach}

Foraging can be viewed as a process by which a forager gathers information on resources. An advantage of foraging in groups is that conspecifics may provide public information [81], which may be more readily available in the large aggregations of red knots in the Wadden Sea. The use of public information by red knots from the Wadden Sea has been shown in an experimental setting [17]. Together with public information, foragers can also make use of personal information from previous experiences. A resource landscape that is stable over time allows foragers to return to suitable foraging locations and thus facilitate site fidelity [6]. If personal experience increases the efficiency of the used foraging strategy, a foraging strategy may become self-reinforcing. Such positive feedback enhances between-individual differences in strategies and could promote solitary foraging. Moreover, several studies have shown that red knots' digestive physiology adjusts to dietary differences, which may drive foraging decisions even further apart [50, 82]. The analysis of droppings showed that red knots at Banc d'Arguin had a more diverse diet than red knots in the Wadden Sea, who had a virtually monospecific diet of cockles. We did not study dietary differences between individuals, but a part of the 
diet diversity at Banc d'Arguin may well be the result of different individuals having different diet specializations, as proposed by previous studies [36, 50, 77]. We note, however, that also when feeding in groups on monospecific diets in the Wadden Sea, red knots appear to differ in their individual diet preferences, for example with respect to the range of prey qualities they accept $[49,82]$.

\section{The development of space use}

We have shown that space use patterns of red knots are not simply a species characteristic, but that they can be explained as a response to the local resource environments. This suggests that when predicting the ecological effects of environmental change, animal space use characteristics should not be assumed to remain stable. Unfortunately, it is difficult to tell what must be assumed instead. If the observed space use differences largely result from genetic differences between the two populations, then adjustment to environmental change would take many generations. Behavioural differences may also result from environmental effects on development, which would imply that adjustment to environmental change can happen in one generation [83, 84]. Even more directly, differences in space use patterns may be explained by direct behavioural responses to the environment, in which case adjustment to changing environments could be instantaneous. The observation that canutus red knots blend in with islandica red knots when visiting the Wadden Sea during migration [44,62] suggests that this last possibility is likely to be predominant.

More insight into these processes could be provided by tracking individual red knots as well as their local environment along the different areas that they visit during their annual migratory cycle, or even over multiple years in the same areas. Even if the state of animal tracking technology may restrict the application of such methods, it seems more challenging to track the changes in the resource landscapes experienced by individuals in sufficient spatial and temporal detail. Right now, it may not be the tracking technology that limits progress [85], but the grain size at which we can measure relevant aspects of the environment.

\section{Conclusions}

Foraging red knots in the Wadden Sea showed a high degree of aggregation, whereas foraging red knots at Banc d'Arguin did not. In contrast, red knots in the Wadden Sea did not show site fidelity, which the Banc d'Arguin red knots did. These contrasting strategies (grouping nomads versus solitary residents) fit with the observed differences in the resource landscapes. The single prey species in the Wadden Sea occurred in large patches, which allowed red knots to forage in large groups. Contrarily, the multiple prey species at Banc d'Arguin occurred scattered in small patches, which increases interference competition but may allow foragers to monopolize a patch and postpone depletion. We conclude that space use patterns by red knots are not simply a species characteristic, but can be explained as a response to the local resource environments.

\section{Additional file}

Additional file 1: Supplementary material. (PDF $430 \mathrm{~kb}$ )

\section{Abbreviations}

AFDM flesh: Ash-free dry flesh mass; $D_{\text {shell: Dry shell mass }}$

\section{Acknowledgments}

First and foremost, we thank the staff of the Parc National du Banc d'Arguin (PNBA) and the people of Iwik for enabling and facilitating everything that comes with a technology-intense tracking study in the Baie d'Aouatif, and Otto Overdijk of Vereniging Natuurmonumenten for facilitating similar work around Griend. Many people provided essential help in the field and laboratory, including Emma Penning, Ginny Chan, Wouter Splinter, Marwa Kavelaars, Jimmy de Fouw, John Cluderay, Ahmadou Abderahmane Sall, Sidi Cheikh, Hacen ould Mohamed el Hacen, Lenze Hofstee, Janne Ouwehand and Petra de Goeij. José Alves was of critical help during the catch of birds on Zira. We thank Will Cresswell and an anonymous reviewer for constructive comments on an earlier draft.

\section{Funding}

This research was funded by an NWO-VIDI grant awarded to JAvG (grant number 864.09.002) and an NWO-TOP grant ('Shorebirds in space', grant number 854.11.004) awarded to TP.

\section{Availability of data and materials}

All data used in this study is available at https://doi.org/10.5281/ zenodo.1569153.

\section{Authors' contributions}

TP, TO, AIB and JAvG conceived the study. TO, AIB, TP, MVAS, MEF, AD, SH and JAvG collected the data in Mauritania. AIB, TP, AD, SH and JtH collected the data in The Netherlands. TO wrote the initial draft, and subsequent revisions benefitted from contributions by all authors. All authors read and approved the final manuscript.

Ethics approval and consent to participate

All research, including animal experiments, was carried out according to Dutch law (DEC license NIOZ 10.04).

Consent for publication

Not applicable.

Competing interests

The authors declare that they have no competing interests.

\section{Publisher's Note}

Springer Nature remains neutral with regard to jurisdictional claims in published maps and institutional affiliations.

\section{Author details}

${ }^{1} \mathrm{NIOZ}$ Royal Netherlands Institute for Sea Research, Department of Coastal Systems, and Utrecht University, P.O. Box 59, 1790 AB Den Burg, Texel, The Netherlands. ${ }^{2}$ Centre for Biological Diversity, School of Biology, University of St Andrews, Fife KY16 9TF, UK. ${ }^{3}$ Rudi Drent Chair in Global Flyway Ecology, Conservation Ecology Group, Groningen Institute for Evolutionary Life Sciences (GELIFES), University of Groningen, PO Box 11103, 9700 CC

Groningen, The Netherlands. ${ }^{4} E B I O M E$ Ecobiologie Marine et Environnement, Département de Biologie, Université de Nouakchott Al-Aasriya, BP. 880 Nouakchott, Mauritania. ${ }^{5}$ Present Address: Sorbonne Université, CNRS, Station 
Biologique de Roscoff, Laboratoire Adaptation et Diversité en Milieu Marin, UMR 7144, CS90074, 29688 Roscoff Cedex, France.

\section{Received: 7 June 2018 Accepted: 14 November 2018} Published online: 20 December 2018

\section{References}

1. Stephens DW, Krebs JR. Foraging Theory. New Jersey: Princeton University Press; 1986.

2. Fretwell SD, Lucas HL. On territorial behaviour and other factors influencing habitat distribution in birds. Acta Biotheor. 1970;19:16-36. https://doi.org/10. 1007/BF01601953.

3. Sutherland WJ. Aggregation and the 'ideal free' distribution. J Anim Ecol. 1983;52:821-8. https://doi.org/10.2307/4456.

4. Tregenza T. Building on the ideal free distribution. In Advances in Ecological Research (eds. Begon M., Fitter A.H.), pp. 253-307: Academic Press; 1995.

5. Wakefield ED, Bodey TW, Bearhop S, Blackburn J, Kendrew DR, Dwyer RG, et al. Space partitioning without territoriality in gannets. Science. 2013;341:6870. https://doi.org/10.1126/science.1236077.

6. Switzer PV. Site fidelity in predictable and unpredictable habitats. Evol Ecol. 1993;7:533-55. https://doi.org/10.1007/BF01237820.

7. Börger L, Dalziel BD, Fryxell JM. Are there general mechanisms of animal home range behaviour? A review and prospects for future research. Ecol Lett. 2008;11:637-50. https://doi.org/10.1111/j.1461-0248.2008.01182.x.

8. Fryxell JM, Hazell M, Börger L, Dalziel BD, Haydon DT, Morales JM, et al. Multiple movement modes by large herbivores at multiple spatiotemporal scales. PNAS. 2008;105:19114-9. https://doi.org/10.1073/pnas.0801737105.

9. van Moorter B, Rolandsen CM, Basille M, Gaillard J-M. Movement is the glue connecting home ranges and habitat selection. J Anim Ecol. 2016;85:21-31. https://doi.org/10.1111/1365-2656.12394.

10. Bartumeus F, Campos D, Ryu WS, Lloret-Cabot R, Méndez V, Catalan J. Foraging success under uncertainty: search tradeoffs and optimal space use. Ecol Lett. 2016;19:1299-313. https://doi.org/10.1111/ele.12660.

11. Spiegel O, Leu ST, Bull CM, Sih A. What's your move? Movement as a link between personality and spatial dynamics in animal populations. Ecol Lett. 2017;20:3-18. https://doi.org/10.1111/ele.12708.

12. Bastille-Rousseau G, Gibbs JP, Yackulic CB, Frair JL, Cabrera F, Rousseau L-P et al. Animal movement in the absence of predation: environmental drivers of movement strategies in a partial migration system. Oikos. 2017;126:100419. https://doi.org/10.1111/oik.03928.

13. Weimerskirch $\mathrm{H}$. Are seabirds foraging for unpredictable resources? Deep Sea Res Pt II 2007;54:211-23. https://doi.org/10.1016/j.dsr2.2006.11.013.

14. Barraquand F, Benhamou S. Animals movements in heterogeneous landscapes: identifying profitable places and homogeneous movement bouts. Ecology. 2008;89:3336-48. https://doi.org/10.1890/08-0162.1.

15. Lima SL, Dill LM. Behavioral decisions made under the risk of predation: a review and prospectus. Can J Zool. 1990;68:619-40. https://doi.org/10.1139/z90-092.

16. Giraldeau L-A, Caraco T. Social Foraging Theory: Princeton University Press; 2000.

17. Bijleveld Al, van Gils JA, Jouta J, Piersma T. Benefits of foraging in small groups: an experimental study on public information use in red knots Calidris canutus. Behav Process. 2015;117:74-81. https://doi.org/10.1016/j. beproc.2014.09.003.

18. Goss-Custard JD. Competition for food and interference amongst waders. Ardea. 1980;68:31-52. https://doi.org/10.5253/arde.v68.p31.

19. Vahl WK, Lok T, van der Meer J, Piersma T, Weissing FJ. Spatial clumping of food and social dominance affect interference competition among ruddy turnstones. Behav Ecol. 2005;16:834-44. https://doi.org/10.1093/beheco/ari067

20. Pulliam HR, Caraco T. Living in groups: is there an optimal group size? In Behavioural Ecology: an Evolutionary Approach (eds. Krebs J.R., Davies N.B.), pp. 122-47. Sunderland, MA: Sinauer Associates; 1984.

21. Duijns S, Knot IE, Piersma T, Gils JA. Field measurements give biased estimates of functional response parameters, but help explain foraging distributions. J Anim Ecol. 2015:84:565-75. https://doi.org/10.1111/1365-2656.12309

22. Bijleveld Al, Folmer EO, Piersma T. Experimental evidence for cryptic interference among socially foraging shorebirds. Behav Ecol. 2012;23:806-14. https://doi.org/10.1093/beheco/ars034.

23. van Moorter B, Bunnefeld N, Panzacchi M, Rolandsen CM, Solberg EJ, Sæther B-E. Understanding scales of movement: animals ride waves and ripples of environmental change. J Anim Ecol. 2013;82. https://doi.org/10. $1111 / 1365-2656.12045$
24. Sutherland WJ, Anderson CW. Predicting the distribution of individuals and the consequences of habitat loss: the role of prey depletion. J Theor Biol. 1993;160:223-30. https://doi.org/10.1006/jtbi.1993.1015.

25. Brown JL. The evolution of diversity in avian territorial systems. Wilson Bull. 1964:160-9. https://www.jstor.org/stable/4159278

26. VahI WK, Kingma SA. Food divisibility and interference competition among captive ruddy turnstones, Arenaria interpres. Anim Behav. 2007;74:1391-401. https://doi.org/10.1016/j.anbehav.2007.01.006.

27. Brown JL, Orians GH. Spacing patterns in mobile animals. Annu Rev Ecol Syst. 1970;1:239-62. https://www.jstor.org/stable/2096773.

28. Myers JP. Territoriality and flocking by buff-breasted sandpipers: variations in non-breeding dispersion. Condor. 1980;82:241-50. https:// doi.org/10.2307/1367387.

29. Ens BJ. Feeding territories in curlews (20Y revisited). Wader Study Group Bull. 1983;39:49-50.

30. Colwell MA. A review of territoriality in non-breeding shorebirds (Charadrii). Wader Study Group Bull. 2000;93:58-66.

31. Tim Tinker M, Guimarães PR, Novak M, Marquitti FMD, Bodkin JL, Staedler M, et al. Structure and mechanism of diet specialisation: testing models of individual variation in resource use with sea otters. Ecol Lett. 2012;15:47583. https://doi.org/10.1111/j.1461-0248.2012.01760.x.

32. Patrick SC, Bearhop S, Grémillet D, Lescroël A, Grecian WJ, Bodey TW, et al. Individual differences in searching behaviour and spatial foraging consistency in a central place marine predator. Oikos. 2014;123:33-40. https://doi.org/10.1111/j.1600-0706.2013.00406.x

33. van Gils JA, de Rooij SR, van Belle J, van der Meer J, Dekinga A, Piersma T, et al. Digestive bottleneck affects foraging decisions in red knots Calidris canutus. I Prey choice J Anim Ecol. 2005;74:105-19. https://doi.org/10.1111/j. 1365-2656.2004.00903.x.

34. van Gils JA, van der Geest M, Leyrer J, Oudman T, Lok T, Onrust J, et al. Toxin constraint explains diet choice, survival and population dynamics in a molluscivore shorebird. Proc R Soc B Biol Sci. 2013;280:20130861. https://doi. org/10.1098/rspb.2013.0861.

35. Oudman T, Onrust J, de Fouw J, Spaans B, Piersma T, van Gils JA. Digestive capacity and toxicity cause mixed diets in red knots that maximize intake rate. Am Nat. 2014;183:650-9. https://doi.org/10.1086/675759

36. Oudman T, Hin V, Dekinga A, van Gils JA. The effect of digestive capacity on the intake rate of toxic and non-toxic prey in an ecological context. PLoS One. 2015;10:e0136144. https://doi.org/10.1371/journal.pone.0136144.

37. Hopcraft JGC, Morales JM, Beyer HL, Borner M, Mwangomo E, Sinclair ARE, et al. Competition, predation, and migration: individual choice patterns of Serengeti migrants captured by hierarchical models. Ecol Monogr. 2014;84: 355-72. https://doi.org/10.1890/13-1446.1.

38. Avgar T, Mosser A, Brown GS, Fryxell JM. Environmental and individual drivers of animal movement patterns across a wide geographical gradient. J Anim Ecol. 2013;82:96-106. https://doi.org/10.1111/j.13652656.2012.02035.x.

39. Sims DW, Southall EJ, Humphries NE, Hays GC, Bradshaw CJA, Pitchford JW, et al. Scaling laws of marine predator search behaviour. Nature. 2008;451: 1098-102. https://doi.org/10.1038/nature06518.

40. Guilford T, Freeman R, Boyle D, Dean B, Kirk H, Phillips R, et al. A dispersive migration in the Atlantic puffin and its implications for migratory navigation. PLoS One. 2011;6:e21336. https://doi.org/10.1371/ journal.pone.0021336.

41. Piersma T. Using the power of comparison to explain habitat use and migration strategies of shorebirds worldwide. J Ornithol. 2007;148(Suppl 1): S45-59. https://doi.org/10.1007/s10336-007-0240-3.

42. Buehler DM, Baker AJ, Piersma T. Reconstructing palaeoflyways of the late Pleistocene and early Holocene red knot Calidris canutus. Ardea. 2006;94:485.

43. Buehler DM, Baker AJ. Population divergence times and historical demography in red knots and dunlins. Condor. 2005;107:497-513. https:// doi.org/10.1650/0010-5422(2005)107[0497:pdtahd]2.0.co;2.

44. Nebel S, Piersma T, van Gils JA, Dekinga A, Spaans B. Length of stopover, fuel storage and a sex-bias in the occurrence of two subspecies of red knots Calidris C. canutus and C.c. islandica in the Dutch Wadden Sea during southward migration. Ardea. 2000;88:65-76.

45. van Gils JA, Spaans B, Dekinga A, Piersma T. Foraging in a tidally structured environment by red knots (Calidris canutus): ideal, but not free. Ecology. 2006:87:1189-202. https://doi.org/10.1890/00129658(2006)87[1189:fiatse]2.0.co;2. 
46. Wiersma P, Piersma T. Effects of microhabitat, flocking, climate and migratory goal on energy expenditure in the annual cycle of red knots. Condor. 1994;96:257-79. https://doi.org/10.2307/1369313.

47. MacCurdy RB, Gabrielson RM, Cortopassi KA. Automated wildlife radio tracking. In Handbook of Position Location: Theory, Practice and Advances (eds. Zekavat S.A., Buehrer R.M.): John Wiley \& Sons; 2012.

48. Piersma T, MacCurdy RB, Gabrielson RM, Cluderay J, Dekinga A, Spaulding E, et al. Fine-scale measurements of individual movements within bird flocks: the principles and three applications of TOA tracking. Limosa. 2014;87:156-67.

49. Bijleveld Al, MacCurdy RB, Chan Y-C, Penning E, Gabrielson RM, Cluderay J, et al. Understanding spatial distributions: negative density-dependence in prey causes predators to trade-off prey quantity with quality. Proc R Soc B Biol Sci. 2016;283:20151557. https://doi.org/10.1098/rspb.2015.1557

50. Oudman T, Bijleveld Al, Kavelaars MM, Dekinga A, Cluderay J, Piersma T, et al. Diet preferences as the cause of individual differences rather than the consequence. J Anim Ecol. 2016;85:1378-88. https://doi.org/10.1111/ 1365-2656.12549.

51. Piersma T, Davidson NC. The migrations and annual cycles of five subspecies of knots in perspective. Wader Study Group Bull. 1992;64:187-97.

52. Warnock N, Warnock S. Attachment of radio-transmitters to sandpipers: review and methods. Wader Study Group Bull. 1993;70:28-30.

53. MacCurdy RB, Bijleveld Al, Gabrielson RM, Cortopassi KA. Automated wildlife radio tracking. In Handbook of Position Location: Theory, Practice, and Advances (eds. Zekavat S.a., Buehrer R.M.), 2nd ed. Hoboken, New Jersey: John Wiley \& Sons; 2019.

54. Piersma T, van Gils JA, de Goeij P, van der Meer J. Holling's functionalresponse model as a tool to link the food-finding mechanism of a probing shorebirds with its spatial distribution. J Anim Ecol. 1995;64:493-504. https:// doi.org/10.2307/5652.

55. van Gils JA, Lisovski S, Lok T, Meissner W, Ożarowska A, de Fouw J, et al. Body shrinkage due to Arctic warming reduces red knot fitness in tropical wintering range. Science. 2016;352:819-21. https://doi.org/10.1126/science.aad6351

56. de Fouw J, van der Heide T, Oudman T, Maas LRM, Piersma T, van Gils JA. Structurally complex seagrass obstructs the sixth sense of a specialized avian molluscivore. Anim Behav. 2016;115:55-67. https://doi.org/10.1016/j. anbehav.2016.02.017.

57. Lavielle M. Using penalized contrasts for the change-point problem. Signal Processing. 2005:85:1501-10. https://doi.org/10.1016/j.sigpro.2005.01.012.

58. van Bemmelen R, Moe B, Hanssen SA, Schmidt NM, Hansen J, Lang J, et al. Flexibility in otherwise consistent non-breeding movements of a longdistance migratory seabird, the long-tailed skua. Mar Ecol Prog Ser. 2017 197-211. https://doi.org/10.3354/meps12010.

59. Bulla M, Oudman T, Bijleveld Al, Piersma T, Kyriacou CP. Marine biorhythms: bridging chronobiology and ecology. Philos Trans R Soc B Biol Sci. 2017; 20160253. https://doi.org/10.1098/rstb.2016.0253.

60. Spiegel O, Leu ST, Sih A, Bull CM. Socially interacting or indifferent neighbours? Randomization of movement paths to tease apart social preference and spatial constraints. Methods Ecol Evol. 2016;7:971-9. https:// doi.org/10.1111/2041-210X.12553.

61. Bijleveld Al, van Gils JA, van der Meer J, Dekinga A, Kraan C, van der Veer $H W$, et al. Designing a benthic monitoring programme with multiple conflicting objectives. Methods Ecol Evol. 2012;3:526-36. https://doi.org/10. 1111/j.2041-210X.2012.00192.x.

62. Piersma T, Hoekstra R, Dekinga A, Koolhaas A, Wolf P, Battley $P$, et al. Scale and intensity of intertidal habitat use by knots Calidris canutus in the western Wadden Sea in relation to food, friends and foes. Neth J Sea Res. 1993;31:331-57. https://doi.org/10.1016/0077-7579(93)90052-T

63. Zwarts $\mathrm{L}$. Seasonal variation in body weight of the bivalves Macoma balthica, Scrobicularia plana, Mya arenaria and Cerastoderman edule in the Dutch Wadden Sea. Neth J Sea Res. 1991;28:231-45. https://doi.org/10.1016/ 0077-7579(91)90021-R

64. Dekker R. Number, growth, biomass and production of organic and calacareous matter of Hydrobia ulvae (Gastropoda: Prosobranchia) in the western Dutch Wadden Sea. (NIOZ-report 1979-15, Netherlands Institute for Sea Research, Texel, The Netherlands; 1979. https://doi.org/10.1890/14-1845.1

65. Bijleveld Al, Twietmeyer S, Piechocki J, van Gils JA, Piersma T. Natural selection by pulsed predation: survival of the thickest. Ecology. 2015;96:1943-56.

66. Dekinga A, Piersma T. Reconstructing diet composition on the basis of faeces in a mollusc-eating wader, the knot Calidris canutus. Bird Study. 1993; 40:144-56. https://doi.org/10.1080/00063659309477140.
67. Onrust J, de Fouw J, Oudman T, van der Geest M, Piersma T, van Gils JA. Red knot diet reconstruction revisited: context dependence revealed by experiments at banc d'Arguin, Mauritania. Bird Study. 2013;60:298-307. https://doi.org/10.1080/00063657.2013.811213.

68. van Gils JA, Battley PF, Piersma T, Drent R. Reinterpretation of gizzard sizes of red knots world-wide emphasises overriding importance of prey quality at migratory stopover sites. Proc R Soc B Biol Sci. 2005;272:2609-18. https:// doi.org/10.1098/rspb.2005.3245.

69. van Gils JA, Piersma T, Dekinga A, Dietz MW. Cost-benefit analysis of mollusc-eating in a shorebird II. Optimizing gizzard size in the face of seasonal demands. J Exp Biol 2003;206:3369-3380. (https://doi.org/10. 1242/Jeb.00546).

70. Dietz MW, Dekinga A, Piersma T, Verhulst S. Estimating organ size in small migrating shorebirds with ultrasonography: an intercalibration exercise. Physiol Biochem Zool. 1999;72:28-37. https://doi.org/10.1086/316648

71. Dekinga A, Dietz MW, Koolhaas A, Piersma T. Time course and reversibility of changes in the gizzards of red knots alternately eating hard and soft food. J Exp Biol. 2001;204:2167-73.

72. Bjornstad ON, Cai J. Package ncf. R package version 1.2-6. 2018.

73. Kraan C, van der Meer J, Dekinga A, Piersma T. Patchiness of macrobenthic invertebrates in homogenized intertidal habitats: hidden spatial structure at a landscape scale. Mar Ecol Prog Ser. 2009;383:211-24. https://doi.org/10. 3354/meps07994.

74. Kraan C, Van Gils JA, Spaans B, Dekinga A, Bijleveld Al, Van Roomen M, et al. Landscape-scale experiment demonstrates that Wadden Sea intertidal flats are used to capacity by molluscivore migrant shorebirds. J Anim Ecol. 2009; 78:1259-68. https://doi.org/10.1111/j.1365-2656.2009.01564.x.

75. Piersma T. What is habitat quality? Dissecting a research portfolio on shorebirds. In Birds and Habitat: Relationships in Changing Landscapes (ed. Fuller R), pp 383-407. Cambridge (UK): Cambridge University Press; 2012.

76. Brown JS, Kotler BP. Hazardous duty pay and the foraging cost of predation. Ecol Lett. 2004;7:999-1014. https://doi.org/10.1111/j.1461-0248.2004.00661.x.

77. van den Hout PJ, van Gils JA, Robin F, van der Geest M, Dekinga A, Piersma T. Interference from adults forces young red knots to forage for longer and in dangerous places. Anim Behav. 2014;88:137-46. https://doi.org/10.1016/j. anbehav.2013.11.020.

78. van den Hout PJ, Piersma T, ten Horn J, Spaans B, Lok T. Individual shifts toward safety explain age-related foraging distribution in a gregarious shorebird. Behav Ecol. 2016;28:419-28. https://doi.org/10.1093/beheco/arw173.

79. Bijlsma RG. Predation by large falcons on wintering waders on the Banc d'Arguin, Mauritania. Ardea. 1990;78:75-82.

80. van den Hout PJ, Mathot KJ, Maas LRM, Piersma T. Predator escape tactics in birds: linking ecology and aerodynamics. Behav Ecol. 2009;21:16-25. https://doi.org/10.1093/beheco/arp146.

81. Valone TJ, Templeton JJ. Public information for the assessment of quality: a widespread social phenomenon. Philos Trans R Soc B Biol Sci. 2002;357: 1549-57. https://doi.org/10.1098/rstb.2002.1064.

82. Bijleveld Al, Massourakis G, van der Marel A, Dekinga A, Spaans B, van Gils $J A$, et al. Personality drives physiological adjustments and is not related to survival. Proc R Soc B Biol Sci. 2014;281:20133135. https://doi.org/10.1098/ rspb.2013.3135.

83. West-Eberhard MJ. Developmental Plasticity and Evolution. New York, NY: Oxford University Press; 2003.

84. Piersma T, van Gils JA. The Flexible Phenotype: a Body-Centred Integration of Ecology, Physiology and Behaviour. Oxford: Oxford University Press; 2011.

85. Kays R, Crofoot MC, Jetz W, Wikelski M. Terrestrial animal tracking as an eye on life and planet. Science. 2015;348:aaa2478. https://doi.org/10.1126/ science.aaa 2478

\section{Ready to submit your research? Choose BMC and benefit from:}

- fast, convenient online submission

- thorough peer review by experienced researchers in your field

- rapid publication on acceptance

- support for research data, including large and complex data types

- gold Open Access which fosters wider collaboration and increased citations

- maximum visibility for your research: over $100 \mathrm{M}$ website views per year

At $\mathrm{BMC}$, research is always in progress.

Learn more biomedcentral.com/submission 